\title{
THE MERCANTILIST INDEX OF TRADE POLICY*
}

\author{
James E. Anderson \\ Boston College and NBER
}

\author{
J. Peter Neary \\ University College Dublin
}

March 6, 1998

Revised October 1, 1998

\begin{abstract}
This paper develops and characterizes an index of trade policy restrictiveness defined as the uniform tariff equivalent which maintains the same volume of trade as a given set of tariffs, quotas, and domestic taxes and subsidies. We relate this volume-equivalent index to the Trade Restrictiveness Index, a welfare-equivalent measure, and relate changes in both indexes to changes in the generalised mean and variance of the tariff schedule. Applications to international crosssection and time-series comparisons of trade policy show that the new index frequently gives a very different picture than do standard indexes.
\end{abstract}

(96 words)

JEL: F13

Keywords: International trade policy; tariffs; quotas; Trade Restrictiveness Index; trade liberalisation.

Addresses for Correspondence: James E. Anderson, Department of Economics, Boston College, Chestnut Hill, MA 02167-3806, USA; Tel.: (+1) 617-552-3691; FAX: (+1) 617-552-2308; email: James.Anderson@BC.EDU. J. Peter Neary, Department of Economics, University College Dublin, Belfield, Dublin 4, Ireland. Tel.: (+353) 1-283-7198; FAX: (+353) 1-2830068; email: JPNeary@Ollamh.UCD.IE.

* For helpful comments, we are grateful to participants in seminars at the Hong Kong University of Science and Technology and the Stockholm School of Economics. The second author's work on this paper forms part of the International Economic Performance Programme of the Centre for Economic Performance at the London School of Economics, funded by the UK ESRC. 
International trade policies are often compared across countries and over time and for a variety of purposes. Analysts use such measures as arithmetic or trade-weighted average tariffs, Non-Tariff Barrier (NTB) coverage ratios and measures of tariff dispersion. All such measures are without theoretical foundation. In Anderson and Neary (1996), we addressed this problem and provided a rigorous theoretical foundation for the Trade Restrictiveness Index (TRI). This index operationalises the idea of finding a uniform tariff which yields the same real income as the original differentiated tariff structure. We advocated its use in studies of openness and growth and in other applications where it is desirable to have a measure of the restrictiveness of trade policy which is independent of real income.

For purposes of trade negotiations, however, comparing levels of protection with an index which holds constant the level of real income is less appropriate. Nations care about the effect of their partners' policies on their own interests, not their partners' interests. To address this need, our earlier paper proposed in passing an alternative measure to the TRI which we called the Mercantilist Trade Restrictiveness Index (MTRI). This index operationalises the idea of finding a uniform tariff which yields the same trade volume as the original differentiated tariff structure. The purpose of the present paper is to develop fully the properties of the MTRI, to relate them to those of the TRI and of standard atheoretic indexes, and to provide a pilot application. The theory shows that the MTRI will differ, possibly substantially, from the TRI and from the standard indexes. The application bears out this prediction.

The MTRI takes as its starting point the Mercantilist preoccupation with the volume of trade. Modern avatars of Mercantilist thinking are everywhere, and their concern with trade volumes plays an important constraining role. For one example, successive GATT rounds of 
reciprocal trade negotiations have interpreted reciprocity in tariff negotiations to mean equivalent import volume expansion. The WTO goes further, sanctioning retaliation by the offended party to displace a volume of trade equal to that displaced by the original offending protection. (See Bagwell and Staiger (1997) for discussion.) For another example, interest group pleading and even U.S. government negotiators have focused in recent years on trade volumes in auto parts and in semiconductors, as well as on aggregate U.S.-Japanese bilateral trade volumes. The ubiquity of such examples shows that there is a demand on the part of practical trade policy makers for measures of trade restrictiveness which hold trade volume constant. ${ }^{1}$ Such measures should have a useful role to play both as an input to negotiations and as a performance measure of negotiations.

The MTRI is defined as the uniform deflator which, applied to the undistorted traded goods prices, yields the same trade volume (valued at external prices) as the initial set of distortions. ${ }^{2}$ Defining the MTRI as a deflator makes clear its connection with ideal price deflators in general

\footnotetext{
${ }^{1}$ An index of home country tariffs which holds constant the real income of the foreign country is an appealing alternative for a two-country world. In a many-country world, this loses its appeal because an index of Japan's trade distortions can hold constant only one of its trading partners' real incomes. Thus there would be $N-1$ different indexes of each country's trade policies, differing from each other in complex and unintuitive ways. A single constant-volume index treats no one trading partner as special and is appealing as a summary of a country's restrictiveness relative to the rest of the world.

2 This definition of the MTRI compares an arbitrary tariff structure with free trade. More generally, when two different tariff structures are compared, the MTRI is defined as the uniform deflator which, applied to the new set of distorted prices, yields the same trade volume as the initial set of distortions.
} 
equilibrium (see Anderson and Neary, 1996). The MTRI is the general equilibrium version of an index earlier proposed by Corden (1966), which in a quantity index form was independently proposed by Leamer (1974). ${ }^{3}$

The main objective of the theoretical section of the paper is to relate the MTRI to the TRI and to standard atheoretic measures. In particular, we show how changes in both indexes can be characterised fully in terms of changes in two summary measures of the tariff structure, which we call the generalised mean and generalised variance of tariffs. These theoretical linkages are of interest in themselves, especially since they imply that the MTRI must exceed the TRI when trade policies are compared with free trade. In addition, the theoretical results help to explain the clear patterns which emerge from the empirical comparisons of these measures.

For the practitioner, this paper offers a consistent index number of trade restrictiveness which meets the Mercantilist concern with trade volume. The practical analyst is confounded at present by the thousands of different trade barriers and the absence of a theoretically based index number to summarize them. The paper concentrates on tariffs, but also offers an approach to the evaluation of quotas. ${ }^{4}$ By offering the first application of the MTRI, the paper shows that use

\footnotetext{
${ }^{3}$ Neither the Corden nor the Leamer indexes include the disposition of tariff revenue in the analysis. Hence they are not full general equilibrium indexes.

${ }^{4}$ Domestic taxes and subsidies in goods and factor markets can also affect trade significantly, as shown by their prominence in recent policy negotiations. Anderson, Bannister and Neary (1995) extend the TRI to take account of such domestic distortions. A volume-equivalent index of the trade restrictiveness of domestic distortions is readily constructed by combining the methods of this paper with that one.
} 
of a proper index makes a great deal of difference.

Section 1 sets out the basic model of the economy and defines the MTRI. Section 2 derives the properties of the MTRI and relates them to the properties of the average tariff and other indexes, especially the TRI. Section 3 extends the MTRI to cover the case of quotas. Section 4 presents the empirical analysis, which uses a 25-country cross-section of data from around 1990, and a 5-country panel of year-on-year changes from the late 1980's. The MTRI differs from standard indexes in its implications, often dramatically. It also differs substantially from the TRI.

\section{Theory}

The economy is assumed to be in competitive equilibrium, to have no distortions other than tariffs, and to be characterized by a single representative consumer. Traded goods prices are fixed on world markets. (Relaxing these assumptions leads to well-understood complications without adding any insight. In practice, the index we develop can be calculated in the context of any operational model economy.) Section 1.1 lays out the basic formal model of a tariff-distorted open economy, Section 1.2 introduces the import and import volume functions and Section 1.3 defines the MTRI.

\subsection{The Model of a Tariff-Distorted Open Economy}

The behaviour of the private sector is described by the trade expenditure function $E(\pi, u)$. This function gives the expenditure needed by the representative consumer to attain the utility 
level $u$ facing the price vector $\pi$ of traded goods subject to tariffs, net of the income it receives from its ownership of the factors of production. Both of these in turn are represented by standard expenditure and GDP functions respectively:

$$
E(\pi, u)=e(\pi, u)-g(\pi) .
$$

In the background are factor endowments, prices of non-traded goods and factors (which are endogenous given $\pi$ and $u$ ), and prices of traded goods not subject to tariffs. Standard properties of the underlying functions (Shephard's and Hotelling's Lemmas) allow us to identify the price derivatives of the trade expenditure function as the economy's general-equilibrium utilitycompensated (or Hicksian) import demand functions:

$$
E_{\pi}(\pi, u)=m^{c}(\pi, u)
$$

For later use, we note the derivatives of these functions:

$$
m_{u}^{c}=e_{\pi u}=e_{u} x_{I} \quad m_{\pi}^{c}=E_{\pi \pi} .
$$

In words, the utility derivatives of the import demand functions equal the Marshallian income derivatives of demand $x_{I}$ scaled by the marginal cost of utility $e_{u}$; while the matrix of price derivatives equals the Hessian of $E$ and so is negative semi-definite (which for convenience and with little loss of generality we strengthen henceforth to negative definite).

The trade expenditure function completely summarises private-sector behaviour in our model economy. In the presence of tariffs, we must add to this the behaviour of the government, whose sole activity is to collect tariff revenue and rebate it to the representative consumer in a lump 
sum. The outcome of both public and private behaviour is summarised by the balance of trade function: ${ }^{5}$

$$
B\left(\pi, \pi^{*}, u\right) \equiv E(\pi, u)-\left(\pi-\pi^{*}\right) \cdot E_{\pi}(\pi, u) .
$$

This differs from the trade expenditure function by the tariff revenue term, where the vector $\pi-\pi^{*}$ denotes the tariff wedge between domestic and world prices. The derivative of the balance of trade function with respect to the level of utility is:

$$
B_{u}=e_{u}\left[1-\left(\pi-\pi^{*}\right) \cdot x_{I}\right]
$$

5

This equals $e_{u}$ times the inverse of the shadow price of foreign exchange, which measures the welfare gain to a unit increase in the economy's purchasing power. We assume throughout that it is positive, since otherwise the economy is initially so distorted that welfare would rise if some of its endowment were destroyed. (See Anderson and Neary (1992) for more discussion and references.) As for the derivatives of the balance of trade function with respect to domestic prices, they equal:

$$
B_{\pi}^{\prime}=-\left(\pi-\pi^{*}\right)^{\prime} E_{\pi \pi}
$$

\footnotetext{
${ }^{5}$ All vectors are column vectors; a prime (') denotes a transpose; and a dot (.) denotes a vector inner product.
} 
This vector gives the marginal welfare effects of domestic price changes. Since the balance of trade function equals the amount of foreign exchange needed to sustain utility $u$ facing domestic and world prices $\pi$ and $\pi^{*}$, the fall in $B$ following a tariff increase (which raises the corresponding element of $\pi$ ) is a money metric measure of the resulting welfare cost.

The general equilibrium of the economy is reached when utility is at the level consistent with the balance of trade constraint. This requirement equates the balance of trade function to any lump-sum income received from abroad, denoted by $b$ :

$$
B\left(\pi, \pi^{*}, u\right)=b .
$$

The balance of trade function thus allows us to summarise the equilibrium of an economy subject to tariffs in terms of a single compact equation.

\subsection{Import and Import Volume Functions}

As with an individual consumer, we can relate the economy's Hicksian import demand functions 2 to their Marshallian equivalents. ${ }^{6}$ The latter depend on domestic and world prices and on exogenous income $b: m=m\left(\pi, \pi^{*}, b\right)$. In equilibrium (given by the balance of payments condition 7), the Hicksian and Marshallian import demand functions coincide:

$$
m^{c}(\pi, u)=m\left[\pi, \pi^{*}, B\left(\pi, \pi^{*}, u\right)\right] .
$$

Differentiating this "Slutsky Identity" with respect to $u$ and using 3 and 5 yields:

$$
m_{b}=\left[1-\left(\pi-\pi^{*}\right) \cdot x_{I}\right]^{-1} x_{I}
$$

\footnotetext{
${ }^{6}$ For a more formal derivation, see Neary and Schweinberger (1986).
} 
Thus an increased transfer from abroad raises demand for imports to an extent determined by the marginal income responses $x_{I}$, grossed up by the shadow price of foreign exchange. Differentiating 8 with respect to $\pi$ gives a standard Slutsky decomposition of the effects of price changes into substitution and income effects:

$$
m_{\pi}=m_{\pi}^{c}-m_{b} B_{\pi}^{\prime}
$$

Of course, world prices are fixed, so income effects of domestic price changes arise only to the extent that tariffs are in place. This is seen more clearly by eliminating $B_{\pi}$ using 6 , to obtain an alternative expression for the price derivatives:

$$
m_{\pi}=\left[I+m_{b}\left(\pi-\pi^{*}\right)^{\prime}\right] m_{\pi}^{c}
$$

where $I$ is the identity matrix.

Finally, since we are concerned with the volume of tariff-restricted trade (measured at world prices), it is convenient to express its equilibrium level as a function of the variables characterising the general equilibrium of the economy. This leads to two scalar import volume functions, one compensated:

$$
M^{c}\left(\pi, \pi^{*}, u\right) \equiv \pi^{*} \cdot m^{c}(\pi, u)
$$

and the other uncompensated:

$$
M\left(\pi, \pi^{*}, b\right) \equiv \pi^{*} \cdot m\left(\pi, \pi^{*}, b\right) .
$$

The derivatives of these functions are easily derived from the corresponding derivatives of the import demand functions. Here we note only that the derivative of the Marshallian import 
volume function with respect to exogenous income is:

$$
M_{b}=\pi^{*} \cdot m_{b}=\left[1-\left(\pi-\pi^{*}\right) \cdot x_{I}\right]^{-1} \pi^{*} \cdot x_{I}, \quad 0<M_{b}<1 .
$$

This can be interpreted as the marginal propensity to consume tariff-constrained imports, valued at world prices, and it plays a crucial role in the analysis below. We assume throughout that it lies between zero and one. ${ }^{7}$ Finally, the Slutsky decomposition of the import demand functions given in 10 implies a corresponding decomposition of the price derivatives of the Marshallian import volume function. By analogy with 8 , we can relate the Hicksian and Marshallian import volume functions by a Slutsky identity:

$$
M^{c}\left(\pi, \pi^{*}, u\right)=M\left[\pi, \pi^{*}, B\left(\pi, \pi^{*}, u\right)\right],
$$

which, on differentiation, gives the required decomposition:

$$
M_{\pi}=M_{\pi}^{c}-M_{b} B_{\pi}^{\prime}
$$

Armed with these results, we are ready to define the MTRI and to investigate its properties.

\footnotetext{
${ }^{7}$ This requires $\pi * \cdot x_{I}>0$ and $\pi \cdot x_{I}<1$. These conditions guarantee a positive shadow price of foreign
} exchange. 


\subsection{The Mercantilist Trade Restrictiveness Index}

We wish to compare the restrictiveness of trade policy between two equilibria, denoted by "0" and "1" respectively. Following Anderson and Neary (1996), we define the Mercantilist Trade Restrictiveness Index (MTRI) as the uniform price deflator $\mu$ which, when applied to the prices in the new equilibrium, $\pi^{1}$, yields the same volume (at world prices) of tariff-restricted imports as in the old equilibrium, $M^{0.8}$

$$
\mu\left(\pi^{1}, M^{0}\right) \equiv\left\{\mu: M\left(\pi^{1} / \mu\right)=M^{0}\right\}
$$

We simplify notation by dropping the explicit dependence of the trade volume on the exogenous variables $\pi^{*}$ and $b$, which are set at their period-0 values.

The interpretation of the MTRI depends on the policy stance in the new equilibrium. If $\pi^{1}$ equals its free trade value $\pi^{*}, \mu$ equals the inverse of the uniform tariff factor which is equivalent in volume to the initial distortion structure. The Mercantilist uniform tariff equivalent is defined as $1 / \mu-1$. For other values of $\pi^{1}, \mu$ equals the uniform tariff factor surcharge which is volumeequivalent to the changes in trade policy.

Reflecting policy concerns similar to those leading to the MTRI, it may be useful to define other members of a group of trade-balance-constrained trade restrictiveness indexes based on the same logic. For example, in U.S.-Japan trade negotiations, the bilateral trade balance is often a focal point. In this case the relevant constraint for the index number for Japan might include both

\footnotetext{
${ }^{8}$ We assume that $\mu$ is unique, neglecting the complications which arise when $M_{\pi} \cdot \pi$ is not one-signed. In practice, we have not encountered multiple solutions in working with a large number of highly distorted trading economies.
} 
Japanese imports and exports to the U.S., both distorted and undistorted. Alternatively, U.S.Japan negotiations have also focused on bilateral trade in particular product groups, such as motor vehicles and parts or electronics. All cases in this class can be straightforwardly developed using the tools above.

\section{Relation to Other Indexes}

Useful insight into the meaning of the MTRI is gained by analyzing its relationship with other index numbers. The analysis also helps put in perspective the empirical results in Section 4. We first lay out the MTRI, the TRI and the trade-weighted average tariff in a comparable local rate of change format in Section 2.1. We then show in Section 2.2 that changes in both the MTRI and the TRI can be fully characterised in terms of changes in the generalised mean and variance of the tariff schedule. Finally, Section 2.3 compares the levels of the MTRI and TRI.

\subsection{The MTRI, the TRI and the Average Tariff}

Following Anderson and Neary (1996), the TRI is defined as:

$$
\Delta\left(\pi^{1}, u^{0}\right) \equiv\left\{\Delta: B\left(\pi^{1} / \Delta, u^{0}\right)=b^{0}\right\} .
$$

This has a similar uniform tariff deflator interpretation to the MTRI. The difference is that its reference point is the base-period level of utility rather than the volume of trade. The value of $\Delta$ is the uniform tariff deflator which, if applied to the new prices $\pi^{l}$, would ensure balance-ofpayments equilibrium at the initial level of utility. 
Both the MTRI and the TRI are defined in implicit form, so comparing their levels is difficult in general. However, we can say a great deal if we first consider local changes. The proportional rate of change (denoted by a circumflex) of the MTRI is:

$$
\hat{\mu}=\frac{M_{\pi} \cdot d \pi}{M_{\pi} \cdot \pi}
$$

with $M_{\pi}$ evaluated at $\left(\pi^{1} / \mu\right)$. Similarly, the proportional rate of change of the TRI is:

$$
\hat{\Delta}=\frac{B_{\pi} \cdot d \pi}{B_{\pi} \cdot \pi}
$$

where $B_{\pi}$ is evaluated at $\left(\pi^{1} / \Delta, u^{0}\right)$. Each of these in turn may be compared with the change in the trade-weighted average tariff, $\tau^{a}$ :

$$
d \tau^{a}=\frac{E_{\pi} \cdot d \pi}{E_{\pi} \cdot \pi}
$$

Considering these three expressions, we see that, multiplying and dividing by prices in the numerator, each can be written as a weighted sum of the proportional changes in prices $d \pi_{i} / \pi_{i}$. The change in the MTRI in 19 weights proportional price changes by their marginal volumetric shares, $M_{i} \pi_{i} / M_{\pi} \cdot \pi$. The change in the TRI in 20 weights the proportional changes in prices by their marginal welfare shares, $B_{i} \pi_{i} / B_{\pi} . \pi$. Finally, the change in the average tariff in 21 weights proportional price changes by their average trade shares, $E_{i} \pi_{i} / E_{\pi} . \pi$.

An important feature of the MTRI change is that it incorporates the effect of real income changes on trade volume whereas the TRI change does not. To deal appropriately with this, it is 
convenient to define a "compensated" MTRI:

$$
\mu^{c}\left(\pi^{1}, u^{0}, M^{0}\right) \equiv\left\{\mu^{c}: M^{c}\left(\pi^{1} / \mu, u^{0}\right)=M^{0}\right\}
$$

whose rate of change is:

$$
\hat{\mu}^{c}=\frac{M_{\pi}^{c} \cdot d \pi}{M_{\pi}^{c} \cdot \pi} .
$$

Once again, this is a weighted sum of proportional price changes, where the weights can be interpreted as marginal trade shares.

Now, suppose the initial levels of $\mu, \Delta$ and $\mu^{c}$ are the same, as when the new prices are close to the initial prices. Then we can write the rate of change of $\mu$ as a weighted average of the rates of change of the other two indexes:

$$
\hat{\mu}=\lambda \hat{\mu}^{c}+(1-\lambda) \hat{\Delta}
$$

where the weight is simply:

$$
\lambda \equiv \frac{M_{\pi}^{c} \cdot \pi}{M_{\pi} \cdot \pi} .
$$

The weight $\lambda$ is the ratio of the compensated to the uncompensated effect on import volume of a $1 \%$ rise in domestic distorted prices. It is ordinarily between zero and one and it is smaller the more important are income effects relative to substitution effects. (Recall from 11 that $\lambda$ is unity in the neighbourhood of free trade.)

\subsection{Generalised Tariff Moments}


Next, we wish to relate changes in the MTRI and the TRI to changes in the mean and variance of the tariff distribution. This turns out to be possible provided, following Anderson (1995), we work not with trade-weighted tariff moments but with generalised tariff moments, weighted by the elements in the substitution matrix $E_{\pi \pi}$.

First we develop additional notation. Define the ad valorem tariff on good $i$ as $\tau_{i}=\left(\pi_{i}-\pi\right) / \pi$. Let $\underline{x}$ denote a diagonal matrix with the elements of the vector $x$ on the principal diagonal. Then the level of and the change in domestic prices can be written as:

$$
\pi=\underline{\pi}^{*}(1+\tau) \quad d \pi=\underline{\pi}^{*} d \tau,
$$

Next, define the matrix of substitution effects normalised by world prices as:

$$
S \equiv \underline{\pi}^{*} E_{\pi \pi} \underline{\pi}^{*} \frac{1}{\pi^{*} \cdot E_{\pi \pi} \pi^{*}} .
$$

By construction $S$ is a positive definite matrix all of whose elements sum to one: $\imath^{\prime} \mathrm{Sl}=1$, where $\imath$ is a vector of ones. We can now define the generalised average tariff:

$$
\tau \equiv \imath^{\prime} S \tau,
$$

and the generalised variance of tariffs:

$$
V \equiv(\tau-\imath \bar{\tau})^{\prime} S(\tau-\imath \bar{\tau})=\tau^{\prime} S \tau-\bar{\tau}^{2} .
$$


$V$ must be positive (since it is a quadratic form in the positive definite matrix $S$ ) but can be negative if tariffs are non-uniform and disproportionately higher on goods with relatively large cross-substitution effects. ${ }^{9}$ The changes in these generalised moments are:

$$
d \bar{\tau}=\imath^{\prime} S d \tau \text { and } d V=2\left(\tau^{\prime} S d \tau-\bar{\tau} d \bar{\tau}\right)
$$

The change in the variance of tariffs can also be interpreted as twice the (generalised) covariance between initial tariff rates and their changes:

$$
\operatorname{Cov}(\tau, d \tau)=(\tau-\imath \bar{\tau})^{\prime} S(d \tau-\imath d \bar{\tau})=\tau^{\prime} S d \tau-\bar{\tau} d \bar{\tau}=d V / 2
$$

It is now straightforward to express the changes in the three indexes of interest in terms of $d \bar{\tau}$ and $d V$. From 23 and 27, the change in the compensated MTRI is:

$$
\hat{\mu}^{c}=\frac{\mathrm{l}^{\prime} S d \tau}{\mathrm{l}^{\prime} S(\mathrm{l}+\tau)}=\frac{d \bar{\tau}}{1+\bar{\tau}}
$$

Thus the change in the compensated MTRI is identical to the proportionate change in the generalised average tariff. Similarly, the change in the TRI can be expressed as:

$$
\hat{\Delta}=\frac{\tau^{\prime} S d \tau}{\tau^{\prime} S(1+\tau)}=\frac{\bar{\tau} d \bar{\tau}+d V / 2}{\bar{\tau}(1+\bar{\tau})+V}
$$

and the change in the MTRI as: $\frac{\hat{\mu}=\frac{\left(1+M_{b} \tau\right)^{\prime} S d \tau}{\left(1+M_{b} \tau\right)^{\prime} S(l+\tau)}=\frac{\left(1+M_{b} \bar{\tau}\right) d \bar{\tau}+M_{b} d V / 2}{\left(1+M_{b} \bar{\tau}\right)(1+\bar{\tau})+M_{b} V}, \mathbf{3 4}}{{ }^{9} \text { Equation } 28 \text { for the generalised average tariff can be written as } \sum_{i} w_{i} \tau_{i} \text {, where the weights are }}$ defincd as: $w_{i}=\Sigma_{j} S_{j i}$. Recalling that $S$ is defincd to be positive definite, the weight on a given tariff rate is more likely to be positive the higher the own-substitution effect for that good and the more it is complementary with rather than substitutable for other goods. A sufficient condition for all weights to be positive is that the normalised substitution matrix have a dominant diagonal. 
The role of income effects, represented by the marginal propensity to spend on imports $M_{b}$, is clearly crucial: they affect the sensitivity of the MTRI but not of the TRI to changes in the generalised mean and variance of the tariff schedule.

The significance of equations 33 and 34 is that they are completely general, with no restrictions on the types of tariff changes or on the structure of the economy. Their implications can be set out in terms of three propositions and a diagram. First, it is immediate that:

Proposition 1: Assume the denominators of $\hat{\mu}$ and $\hat{\Delta}$ are positive. Then, both the MTRI and the TRI are increasing in the generalised mean and variance of the tariff schedule.

Note that, from 33 and 34, an over-strong sufficient condition for the denominators of both $\hat{\mu}$ and $\hat{\Delta}$ to be positive is that $\bar{\tau}$, the generalised average tariff, be positive.

Next, consider the relative sensitivity of the two indexes to changes in the generalised mean and variance. This is best understood by writing the changes in both indexes as weighted averages of the changes in the two tariff moments. For the TRI, 33 implies:

$$
\hat{\Delta}=\alpha \frac{d \bar{\tau}}{1+\bar{\tau}}+(1-\alpha) \frac{d V}{2 V}, \quad \alpha \equiv \frac{\bar{\tau}(1+\bar{\tau})}{\bar{\tau}(1+\bar{\tau})+V}
$$

Similarly, for the MTRI, 34 implies: ${ }^{10}$

${ }^{10}$ From 24 , it may be checked that $\lambda=(\beta-\alpha) /(1-\alpha)$. Moreover, from 29 and $31, d V / 2 V$ equals the slope coefficient from a generalised least squares regression of $d \tau$ on $\tau$. 


$$
\hat{\mu}=\beta \frac{d \bar{\tau}}{1+\bar{\tau}}+(1-\beta) \frac{d V}{2 V}, \quad \beta \equiv \frac{\left(1+M_{b} \bar{\tau}\right)(1+\bar{\tau})}{\left(1+M_{b} \bar{\tau}\right)(1+\bar{\tau})+M_{b} V}
$$

Using $D_{\alpha}$ and $D_{\beta}$ to denote the denominators of $\alpha$ and $\beta$ respectively, the difference between the weights is:

$$
\beta-\alpha=\frac{(1+\bar{\tau}) V}{D_{\alpha} D_{\beta}}
$$

Assuming the two denominators are positive, $\alpha$ is always less than $\beta$. Thus the TRI is less sensitive than the MTRI to changes in the generalised mean tariff but more sensitive to changes in the generalised variance of tariffs. Finally, the difference between the changes in the two indexes is:

$$
\hat{\Delta}-\hat{\mu}=(\beta-\alpha)\left\{\frac{d V}{2 V}-\frac{d \bar{\tau}}{1+\bar{\tau}}\right\}=\frac{-V d \bar{\tau}+(1+\bar{\tau}) d V / 2}{D_{\alpha} D_{\beta}}
$$

This may be expressed more compactly by defining the generalised coefficient of variation of tariff factors and its rate of change as follows:

$$
C \equiv \frac{V^{1 / 2}}{1+\bar{\tau}} \Rightarrow \hat{C}=\frac{d V}{2 V}-\frac{d \bar{\tau}}{1+\bar{\tau}}
$$

Hence, recalling from 37 that $\beta-\alpha$ is positive provided the denominators of $\alpha$ and $\beta$ are positive, we may conclude:

Proposition 2: Assume that the denominators of $\alpha$ and $\beta$ are positive. Then, starting from the 
same point, the TRI increases by more than the MTRI if and only if the generalised coefficient of variation of tariff factors rises:

$$
\hat{\Delta}>\hat{\mu} \Leftrightarrow \frac{d V}{2 V}>\frac{d \bar{\tau}}{1+\bar{\tau}} \Leftrightarrow \hat{C}>0
$$

The full relationship between changes in the TRI and MTRI on the one hand and changes in the generalised tariff moments on the other is illustrated in Figure 1, drawn in the space of $(d V, d \bar{\tau})$. From Proposition 1, both indexes increase together in the north-east quadrant and fall together in the south-west quadrant. The upward-sloping dashed line is the locus along which $\hat{\Delta}=\hat{\mu}$. Only in the regions denoted I and II (which lie between the $\hat{\Delta}=0$ and $\hat{\mu}=0$ loci), do they move in opposite directions. In Region I, the fall in the generalised average tariff is sufficient to offset the rise in the generalised variance as far as $\mu$ is concerned but not as far as $\Delta$ is concerned: $\mu$ falls and $\Delta$ rises. Exactly the opposite configuration applies in Region II. (From 24, the $\hat{\mu}=0$ locus lies between the $\hat{\Delta}=0$ locus and the $\hat{\mu}^{c}=0$ locus, which from 32 coincides with the vertical axis.) Note that a rise in $\Delta$ is equivalent to a fall in welfare and a rise in $\mu$ is equivalent to a fall in import volume. Hence Figure 1 gives a complete characterisation of the effects on welfare and import volume of arbitrary changes in the generalised tariff moments.

\subsection{Comparing the Levels of the MTRI and TRI}

Having derived the relationships between changes in the MTRI and the TRI, we can now relate their levels, at least for the comparison with free trade. The key result is: 
Proposition 3: The MTRI exceeds the TRI for comparisons with free trade, provided the generalised average tariff is positive. The ranking is strict except when tariffs are uniform, in which case all tariff indexes are equal.

Proof: By definition, $\mu\left(\pi^{0}, M^{0}\right)=\Delta\left(\pi^{0}, M^{0}\right)=1$. In words, when the initial tariff policy does not change, both indexes equal one. Hence, comparing the initial tariff policy $\left(\pi^{0}\right)$ with free trade $\left(\pi^{*}\right)$, the difference between $\mu$ and $\Delta$ is the same as the difference between their proportional rates of change, provided this is one-signed over the relevant interval:

$$
\ln \mu\left(\pi^{*}, M^{0}\right)-\ln \Delta\left(\pi^{*}, u^{0}\right)=\int_{\pi^{0}}^{\pi^{*}}\left\{\hat{\mu}\left(\pi, M^{0}\right)-\hat{\Delta}\left(\pi, u^{0}\right)\right\} d \pi
$$

To find a path in price space from $\pi^{0}$ to $\pi^{*}$ along which the expression in brackets is always nonnegative, we proceed in two stages:

(i) First, we eliminate the dispersion in the initial tariff structure by radial steps:

$$
d \tau=-(\tau-\imath \bar{\tau}) d \varepsilon, \quad d \varepsilon>0
$$

Substituting from 42 into 30, we see that, along this segment of the path, the generalised average tariff is constant $(d \bar{\tau}=0)$ and the generalised variance is falling, provided it was strictly positive to begin with $(d V=-2 V d \varepsilon<0)$. Hence the generalised coefficient of variation is also falling and Proposition 2 applies. With the initial generalised average tariff $\bar{\tau}^{0}$ assumed to be positive, it also follows from 19 and 20 that both indexes are falling. Hence, along this segment of the path, we have $0>\hat{\mu}>\hat{\Delta}$. Continue in this fashion from $\pi^{0}$ to $\pi^{*}\left(1+\bar{\tau}^{0}\right)$, i.e., until all the dispersion in 
the tariff structure is eliminated.

(ii) Next, with $C=V=0$, we implement a uniform radial reduction in tariffs: $d \tau=-\tau d \varepsilon$. Again, from 30, this must reduce the generalised mean tariff $(d \bar{\tau}=-d \varepsilon)$ and leave the generalised variance unchanged (since it was zero to begin with): $d V=-2 V d \varepsilon=0$. Hence, from 33 and 34, both

indexes fall by the same percentage amount along this segment of the path: $0>\hat{\mu}=\hat{\Delta}$. Proceeding along this segment of the path until we reach free trade, the proposition follows immediately.

To interpret the proposition, recall that for comparisons with free trade, $\mu$ and $\Delta$ equal the inverses of the uniform tariff equivalents which are import-volume-equivalent and welfareequivalent to $\pi^{0}$ respectively. So, the facts that $\mu$ exceeds $\Delta$ and that both are less than one means that the welfare-equivalent uniform tariff exceeds the import-volume-equivalent uniform tariff. Thus the tariff levels calculated according to the MTRI logic generally under-estimate the tariff levels which would be appropriate for welfare comparisons.

\section{Quotas and the MTRI}

Quotas are an important form of trade intervention in many countries. Moreover, other kinds of non-tariff barriers may often be represented as quotas. The application of Section 4 includes many examples of non-tariff barriers treated in this way. Thus it is important to extend the definition of the MTRI to incorporate quotas. For simplicity, we continue to assume that all distortions are in trade only. 
Let $q$ denote the vector of quota-constrained goods, with domestic prices $p$ and world prices $p^{*}$; while $m, \pi$ and $\pi^{*}$ continue to denote the quantity and prices of tariff-constrained imports. As before, we seek a scalar deflator which, when applied to the policy variables in the new equilibrium, $\left\{q^{1}, \pi^{1}\right\}$, will yield the same import volume as the old equilibrium, $M^{0}$. However, it would not make sense to deflate the quota vector directly. Instead, we apply the deflation factor to the domestic-market-clearing prices of the quota-constrained goods.

To formalise these ideas, we adapt the techniques developed for the analysis of quotas in Anderson and Neary (1992) and applied to derive the TRI in the presence of quotas by Anderson and Neary (1996). The net expenditure on non-quota-constrained goods, called by Anderson and Neary (1992) the distorted trade expenditure function, is:

$$
\tilde{E}(q, \pi, u) \equiv \max _{p}\{E(p, \pi, u)-p \cdot q\}
$$

where the undistorted trade expenditure function $E$ is defined in a similar manner to 1 . The derivatives of $\mathrm{E}$ with respect to $\pi$ give the compensated import demand functions for goods subject to tariffs, as in earlier sections; while the derivatives with respect to $q$ give (minus) the "virtual" prices of the quotas:

$$
\tilde{E}_{\pi}(q, \pi, u)=m^{c}(q, \pi, u) \quad \tilde{E}_{q}(q, \pi, u)=-p(q, \pi, u) .
$$

Of course, when $\{q, \pi, u\}$ relate to the same equilibrium, the virtual prices equal the marketclearing domestic prices. The distorted balance of trade function can now be defined as:

$$
\tilde{B}(q, \pi, u) \equiv \tilde{E}(q, \pi, u)+p \cdot q-\left(\pi-\pi^{*}\right) \cdot m-\left(p-p^{*}\right)^{\prime}(I-\underline{\omega}) q,
$$


where $m$ and $p$ are determined from 44 and exogenous variables are suppressed to economise on notation. This is more complex than the corresponding undistorted function 4 , since there are now two sets of trade restrictions, and (following standard convention) we assume that the rents generated from each are disbursed differently. The private sector receives all the tariff revenue, as in Section 2, but only some of the quota revenue, with the elements of the $\omega$ vector $\left(0 \leq \omega_{i \leq} l\right)$ denoting the share of quota rents on good $i$ lost to foreigners. Finally, equilibrium utility is determined implicitly by the balance of payments equilibrium condition:

$$
\tilde{B}(q, \pi, u)=b .
$$

These functions allow us to determine the appropriate virtual prices and characterise the equilibrium in the presence of quotas. Next, to define the MTRI itself, we need to define the uncompensated volume-of-trade function given the prices of the quota-constrained goods. The steps in doing this are similar to those followed in Section 1.2. First, the compensated volumeof-trade function is an extension of 12 :

$$
M^{c}(p, \pi, u) \equiv p \cdot E_{p}(p, \pi, u)+\pi^{*} \cdot E_{\pi}(p, \pi, u)
$$

To derive the uncompensated volume-of-trade function from this, we must specify the undistorted balance of trade function. We do this by noting that the undistorted and distorted functions can be equated when the former is evaluated at the appropriate virtual prices. Thus:

$$
B(p, \pi, u)=\tilde{B}(q, \pi, u) \quad \text { when } \quad p=-\tilde{E}_{q}(q, \pi, u)
$$

As in 15 , the uncompensated volume-of-trade function, $M(p, \pi, b)$, can now be defined implicitly 
as follows:

$$
M^{c}(p, \pi, u)=M[p, \pi, B(p, \pi, u)] .
$$

We are finally able to define the MTRI itself:

$$
\mu\left(q^{1}, \pi^{1}, M^{0}\right) \equiv\left\{\mu: M\left(p / \mu, \pi^{1 / \mu}\right)=M^{0}\right\},
$$

where the virtual prices $\mathrm{p}$ are determined endogenously by the requirement that domestic markets for quota-constrained goods clear, i.e., by equations 46 and 48 evaluated at $\left(q^{l}, \pi^{l}\right)$. With the quotas reduced to their price equivalents, the interpretation of the MTRI now proceeds in exactly the same way as in the case of tariffs only.

\section{A Sample Application}

The MTRI can be made operational with only slight modifications of any standard Computable General Equilibrium (CGE) model. All that is necessary is to define the virtual prices $\mathrm{p}$ and the volume of distorted trade $M$. Then the deflator $\mu$ can be calculated. Ideally, the CGE model should be disaggregated with respect to trade distortions (and those domestic distortions which are important in considering trade policy). Most CGE models are highly aggregated with respect to trade and so are not ideally suitable for this purpose. It should be possible, however, with strategic use of nested CES structures, to disaggregate many existing CGE models appropriately.

Applications are chiefly constrained by the paucity of detailed distortion data. While limits on information are notorious for non-tariff distortions, there is also surprisingly little systematic 
detailed information on tariffs and associated import volumes across a broad spectrum of countries and years. Here, we draw on Anderson's (1998) application of the TRI and use the same data and CGE model as a basis for calculating the MTRI and comparing it with the TRI and the standard indexes.

Anderson (1998) develops a tractable CGE model with a highly aggregated CES/CET industrial structure and a very disaggregated trade structure, and calculates the TRI for both a cross section of countries and for a few cases of year-on-year changes. The model's main virtue is that it requires relatively little information about the domestic production structure, so a standard model framework can be used across a large group of countries. At the same time, it permits the use of as detailed trade distortions data as the analyst can find.

Limits on detailed trade and trade distortion data dictate the scope of the results presented below. The data were obtained by the World Bank from the TRAINS (TRade Analysis and INformation System) database (UNCTAD (1996)), supplemented by trade and trade distortions data supplied by country economists at the Bank. Non-Tariff Barriers (NTB's) are treated as binding quotas in the model. To obtain consistent trade flow and trade distortions data, more detailed data are aggregated to the four-digit Harmonized System level using trade-weighted average tariffs, and for NTB's using the procedure that a four-digit category is counted as NTBconstrained if $75 \%$ or more of its elements are "hard-core" NTB-constrained. ${ }^{11}$ Some such

${ }^{11}$ A "hard-core" NTB includes some restrictions which are hardly quantitative, such as being under investigation for dumping. It excludes simple licensing requirements. See UNCTAD's description of their NTB database for details. 
atheoretic aggregation procedure is unavoidable due to inconsistencies in classification systems of the most detailed distortion and trade data.

A key practical issue is the treatment of quota rents, bearing in mind that information on domestic prices (and hence on quota premia) are not available. In simulating the move to free trade (i.e., in Table 1 and Figure 2 below) we assume that rent-retaining tariffs capture all the quota rent, so all NTB's are non-binding at the margin in the initial equilibrium. ${ }^{12}$ Hence the policy regime is assumed to be one of tariffs only, with quotas replaced by their tariff equivalents. In evaluating year-on-year changes (Table 2 below), we assume instead that binding quotas generate rents which are entirely lost to foreigners or to rent seeking, apart from the fraction which is retained by tariffs. Alternative expedients (discussed in Anderson (1998)) lead to similar qualitative results.

Table 1 presents the results of calculating the TRI and MTRI using the CGE model for a cross-section of 25 countries. In this table we are comparing the actual data for the country and year indicated with free trade ( so $\pi^{l}=\pi^{*}$ and $\tau^{l}=0$ ). Hence we present both the TRI and MTRI in terms of their uniform tariff equivalents (i.e., $1 / \Delta-1$ and $1 / \mu-1$ ) to facilitate comparison with the trade-weighted average tariff, $\tau^{a 0}$. To see why this makes sense, we can rewrite the definition of the MTRI from 17 as follows:

$$
M\left[\underline{\pi}^{*}\left(l+\tau^{1}\right) / \mu\right]=M\left[\underline{\pi}^{*}\left(l+\tau^{0}\right)\right]=M^{0} .
$$

\footnotetext{
12 Tariffs on NTB-constrained goods are in practice usually quite high.
} 
With $\tau^{l}=0$, we seek a scalar measure of the vector $\tau^{0}$. The atheoretic measure is the tradeweighted average tariff $\tau^{a 0}$, while the theoretically correct measure is $1 / \mu-1$, the uniform tariff that is import-volume-equivalent to $\tau^{0}$. A similar argument applies to the uniform tariff equivalent of the TRI, $1 / \Delta-1$, which gives the uniform tariff that is welfare-equivalent to $\tau^{0}$. To facilitate comparison of the columns in Table 1, Table 1a presents the results of simple regressions and rank correlations between the columns. 
The Mercantilist Index of Trade Policy

Table 1: Welfare- and Import-Volume-Equivalent Uniform Tariffs

\begin{tabular}{|c|c|c|c|c|c|}
\hline \multirow{3}{*}{ Country and Year } & \multicolumn{3}{|c|}{ Trade-Weighted } & \multirow{2}{*}{\multicolumn{2}{|c|}{$\begin{array}{l}\text { Coefficients } \\
\text { of Variation }\end{array}$}} \\
\hline & \multirow[t]{2}{*}{ TRI } & \multirow{2}{*}{$\begin{array}{c}\text { Average } \\
\text { Tariff }\end{array}$} & \multirow[t]{2}{*}{ MTRI } & & \\
\hline & & & & Final & Intermediate \\
\hline Argentina 1985 & 0.196 & 0.181 & 0.094 & 0.606 & 0.615 \\
\hline Australia 1988 & 0.166 & 0.108 & 0.116 & 0.974 & 0.999 \\
\hline Austria 1988 & 0.200 & 0.106 & 0.124 & 0.790 & 0.865 \\
\hline Bolivia 1991 & 0.093 & 0.094 & 0.093 & 0.167 & 0.088 \\
\hline Brazil 1989 & 0.233 & 0.161 & 0.176 & 0.777 & 0.817 \\
\hline Canada 1990 & 0.095 & 0.070 & 0.079 & 0.633 & 0.857 \\
\hline Colombia 1991 & 0.111 & 0.100 & 0.080 & 0.472 & 0.513 \\
\hline Ecuador 1991 & 0.095 & 0.066 & 0.069 & 0.745 & 0.753 \\
\hline Finland 1988 & 0.126 & 0.060 & 0.059 & 1.164 & 1.517 \\
\hline Hungary 1991 & 0.153 & 0.091 & 0.103 & 0.861 & 0.981 \\
\hline India 1991 & 0.316 & 0.128 & 0.151 & 1.354 & 1.014 \\
\hline Indonesia 1989 & 0.304 & 0.153 & 0.162 & 1.902 & 1.708 \\
\hline Malaysia 1988 & 0.210 & 0.097 & 0.102 & 1.122 & 1.090 \\
\hline Mexico 1989 & 0.124 & 0.108 & 0.114 & 0.425 & 0.502 \\
\hline Morocco 1984 & 0.185 & 0.071 & 0.097 & 1.225 & 2.220 \\
\hline New Zealand 1988 & 0.136 & 0.079 & 0.091 & 0.755 & 1.252 \\
\hline Norway 1988 & 0.084 & 0.045 & 0.046 & 1.355 & 1.297 \\
\hline Paraguay 1990 & 0.178 & 0.125 & 0.132 & 0.750 & 0.862 \\
\hline Peru 1991 & 0.160 & 0.158 & 0.158 & 0.160 & 0.135 \\
\hline Philippines 1991 & 0.173 & 0.142 & 0.146 & 0.463 & 0.512 \\
\hline Poland 1989 & 0.145 & 0.087 & 0.098 & 0.965 & 1.018 \\
\hline Thailand 1988 & 0.447 & 0.320 & 0.344 & 0.741 & 0.571 \\
\hline Tunisia 1988 & 0.186 & 0.099 & 0.092 & 1.278 & 1.311 \\
\hline USA 1990 & 0.061 & 0.039 & 0.048 & 0.916 & 1.133 \\
\hline Venezuela 1991 & 0.211 & 0.129 & 0.145 & 0.838 & 0.663 \\
\hline
\end{tabular}

Notes: All three indexes compare the actual tariff structure with free trade.

Both TRI and MTRI are in uniform tariff equivalent form.

See text for details. 
Table 1a: Regression Equations Based on Columns in Table 1

\begin{tabular}{|l|cccc|}
\hline \multicolumn{1}{|c|}{ Regression Equation } & $a$ & $b$ & $r$ & Rank \\
\hline MTRI on Average Tariff & 0.0073 & 0.9715 & 0.932 & 0.862 \\
MTRI on TRI & $(0.0099)$ & $(0.0787)$ & & \\
& 0.0086 & 0.6164 & 0.881 & 0.691 \\
TRI on Average Tariff & $(0.0134)$ & $(0.0691)$ & & \\
& 0.0349 & 1.2477 & 0.838 & 0.725 \\
(TRI-MTRI)/MTRI on CV(final) & $(0.0213)$ & $(0.1696)$ & & \\
& -5.00 & 68.61 & 0.751 & \\
\hline
\end{tabular}

Notes: $a$ is the intercept and $b$ the slope coefficient; standard errors are in parentheses; $r$ is the correlation coefficient; and "Rank" is the rank correlation coefficent.

Figure 2 illustrates the data from Table 1, with countries ranked by their trade-weighted average tariff. 
Figure 2: Measures of Trade Restrictiveness for 25 Countries Source: All data from Table 1

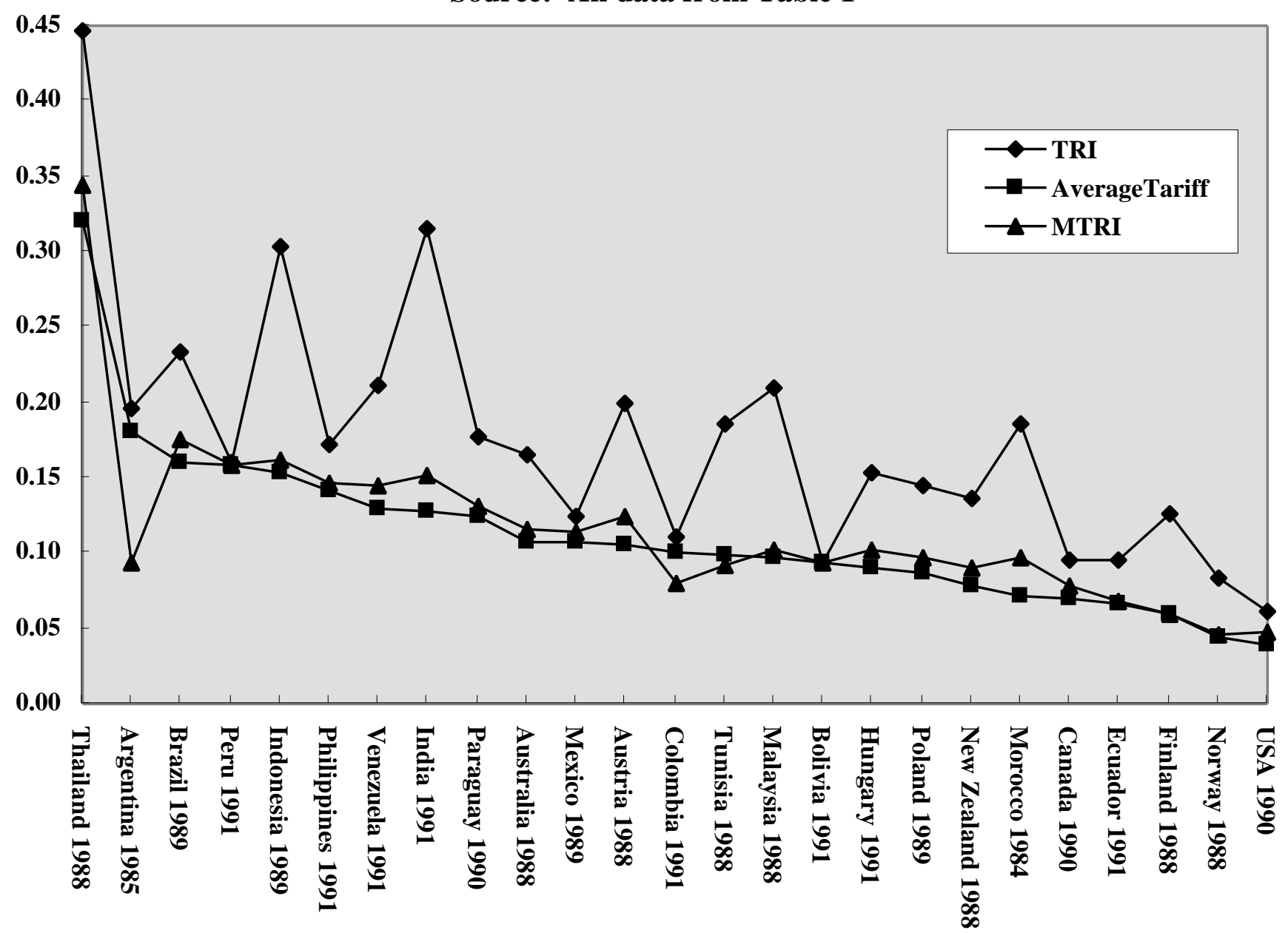

The first conclusion suggested by Table 1 and Figure 2 is that the MTRI and the tradeweighted average tariff tend to move closely together on average. (The correlation and rank correlation coefficients between the two are 0.932 and 0.862 respectively.) However, for individual countries involved in trade negotiations, this does not mean that the two measures are interchangeable. On the contrary, the average tariff underpredicts the MTRI in all but five of the 
twenty-five cases. The effect is not statistically significant (as Table 1a shows) and the underprediction is only $5.6 \%$ on average. However, it is important in a number of individual cases, exceeding 15\% for Austria, Indonesia, New Zealand and the U.S.A. This suggests that in trade negotiations, most countries would prefer to use the MTRI to evaluate their own trade policies but average tariffs to evaluate their partners'. On the other hand, for Argentina and Colombia, the average tariff underpredicts the MTRI by over $20 \%$. So the choice between the two measures is significant and of unpredictable sign in individual cases.

The second conclusion to be drawn from Table 1 and Figure 2 is that the TRI exceeds the MTRI by a significant margin: $53.8 \%$ on average. We know from Proposition 3 that $\mu$ must be greater than $\Delta$ (and hence $1 / \Delta-1$ must be greater than $1 / \mu-1$ ), for comparisons with free trade (at least when both indexes are generated by the same utility-consistent model, as here). This theoretical prediction is borne out for every case in the table. ${ }^{13}$ The relationship between the two is weaker than that between the MTRI and the average tariff (with correlation and rank correlation coefficients of 0.881 and 0.691 respectively). The percentage divergence also varies considerably, ranging from over 100\% in 5 cases to less than 10\% for Bolivia, Mexico and Peru. Here too the theoretical results of Section 2 provide some insight. Proposition 2 showed that, for small changes, $\Delta$ rises by more than $\mu$ if and only the generalised coefficient of variation of tariffs

\footnotetext{
${ }^{13}$ The numbers in the table are given to only three significant digits, so in one case, Bolivia, the values shown for the two indexes are equal to one another. From the raw data, the percentage excess of the TRI over the MTRI for Bolivia is $0.22 \%$, while the next smallest differential (Peru) is $0.88 \%$.
} 
increases. This suggests that the actual coefficient of variation of tariffs might help predict the divergence between the two indexes (since the generalised coefficient is not available in practice). The last two columns in Table 1 give the coefficients of variation for final and intermediate goods respectively and the last line of Table 1a confirms that the percentage excess of the TRI over the MTRI is positively and significantly related to the coefficient of variation of tariffs on final goods. ${ }^{14}$ Overall, it is clear that the two different purposes of evaluating tariff structures yield very different pictures of the relative restrictiveness of nations' trade policies.

Table 2 turns to consider a small sample of year-on-year changes. We now wish to have a measure of the change in the tariff structure from $\tau^{0}$ to $\tau^{1}$. Referring back to 51 , the theoretically correct measure is simply $\mu$ (rather than its uniform tariff equivalent), while the corresponding atheoretic measure is $\left(1+\tau^{a l}\right) /\left(1+\tau^{a 0}\right)$. Thus, a value greater than one in any of the first six numeric columns of the table indicates that, according to the measure in question, trade policy became more restrictive between the two years indicated. Because tariffs on NTB-constrained goods serve the positive function of retaining rent rather than the negative one of restricting trade, we report average tariffs for these separately. We also distinguish between the average tariffs on intermediate and final goods categories. In addition, Table 2 reports the (arithmetic) change in the coefficient of variation of tariffs, and gives information on two measures of NTB restrictiveness: the initial level of and the (arithmetic) change in the NTB coverage ratio, and the (percentage)

${ }^{14}$ Adding the coefficient of variation of tariffs on intermediate goods to the equation adds little explanatory power, with both independent variables insignificant. The correlation between the two coefficients of variation is 0.837 . 
change in the volume of NTB-constrained imports.

Table 2. Year-on-year Comparisons:

The MTRI, TRI and Standard Tariff and Nontariff Measures

\begin{tabular}{|c|c|c|c|c|c|c|c|}
\hline Country/ years & MTRI & $\begin{array}{c}\text { Argentina } \\
85-88 \\
0.783\end{array}$ & $\begin{array}{c}\text { Morocco } \\
84-85 \\
1.044\end{array}$ & $\begin{array}{c}\text { Morocco } \\
86-88 \\
1.044\end{array}$ & $\begin{array}{l}\text { Tunisia } \\
87-88 \\
0.877\end{array}$ & $\begin{array}{l}\text { Tunisia } \\
88-89 \\
0.903\end{array}$ & $\begin{array}{l}\text { Correlat } \\
\text { with MT }\end{array}$ \\
\hline & TRI & 0.783 & 1.098 & 1.028 & 0.913 & 0.862 & $0.95 !$ \\
\hline Average Tariff & No NTB & 1.113 & 0.993 & 0.961 & 0.989 & 1.045 & -0.82 \\
\hline on Final Goods: & NTB & 1.059 & 1.011 & 1.053 & 0.982 & 0.991 & -0.01 \\
\hline Average Tariff on & No NTB & 1.048 & 0.997 & 1.142 & 1.033 & 0.981 & 0.26 \\
\hline Intermediate Goods: & NTB & 0.956 & 0.999 & 1.142 & 0.989 & 1.039 & 0.67 \\
\hline Coefficient of Variat & iбimal & 0.200 & -0.327 & -0.086 & 0.030 & 0.039 & -0.89 \\
\hline of Tariffs: & Intermediate & 0.035 & -0.138 & -0.742 & -0.137 & 0.006 & -0.68 \\
\hline Initial NTB & Final & 0.779 & 0.157 & 0.164 & 0.914 & 0.851 & -0.87 \\
\hline Coverage Ratio: & Intermediate & 0.574 & 0.037 & 0.030 & 0.714 & 0.649 & -0.86 \\
\hline Change in NTB & Final & -0.567 & 0.000 & -0.091 & -0.320 & -0.101 & 0.89 \\
\hline Coverage Ratio: & Intermediate & -0.411 & 0.000 & -0.005 & -0.717 & -0.411 & 0.78 \\
\hline$\%$ Change in Volume & Final & 66.1 & -13.8 & 1.9 & 24.3 & 21.5 & -0.95 \\
\hline $\begin{array}{l}\text { NTB-Constrained } \\
\text { Imports: }\end{array}$ & Intermediate & 35.5 & -2.2 & 15.9 & 23.2 & 13.2 & -0.84 \\
\hline
\end{tabular}

Notes: $\quad$ MTRI and TRI are in level form.

Average tariff measures are in the form: $\left(1+\tau^{\mathrm{a} 1}\right) /\left(1+\tau^{\mathrm{a} 0}\right)$.

Coefficient of variation of tariffs is the arithmetic year-on-year change.

See text for further details.

In dramatic contrast to the results of Table 1, the MTRI in Table 2 differs considerably from

the standard indexes. This echoes the finding of Anderson (1998), where the TRI was shown to

differ dramatically from the average tariff and from all the other standard indicators in evaluating

year-on-year changes in policy. There is a good reason for this. In the hypothetical leap to free

trade, all standard indicators of trade policy move in the same direction. By contrast, in most

real-world trade reforms there are conflicting tendencies which make it much more important to take the structure of index numbers into account. In all cases except the disaggregated average tariffs on intermediate goods, the tariff measures and the MTRI are negatively correlated. As 
might be expected, comparison of the MTRI and the two direct quantitative NTB measures (the change in the NTB coverage ratio and the proportional change in volume of NTB-constrained goods) shows a closer relationship. Many of the countries analysed had a high initial incidence of NTB's and were liberalizing NTB's in the years considered.

Comparing the changes in the MTRI and the TRI, the first columns of Table 2 show that they always have the same sign, but no consistent ranking emerges between them. Surprisingly, in the year-on-year changes, the MTRI and TRI changes are quite highly correlated, with a correlation coefficient above 0.95 .

The results overall show that the MTRI is much different from standard measures in practice, enough to matter to practical policy-making. In future tariff negotiations it should be useful to come equipped with MTRI measures of proposed changes in policy. Of course, all such measures are dependent on the model used to calculate them. Anderson (1998) reports that results are not very sensitive to elasticity values, a finding which applies here as well. This is consistent with the folklore of CGE modelling, that elasticities do not matter much but that specification of the model does matter. (For an illustration in the TRI context, see O'Rourke (1997).) Where MTRI measures are important, it would be useful to have several different calculations based on differing CGE models. Despite these caveats, the case seems to be made that the standard measures are likely to be very seriously misleading in practice. 


\section{Conclusion}

In this paper we have presented a theoretical analysis of the Mercantilist Trade Restrictiveness Index and compared its empirical performance with other measures of trade policy. The MTRI is defined as the uniform tariff which yields the same volume of imports as a given tariff structure. Since it is a true index number for tariffs, the performance of empirical measures should be evaluated in terms of how closely they approximate to the MTRI. We also showed how the properties of the MTRI can be related to changes in the tariff structure, summarised in terms of two parameters, the generalised mean and variance of tariffs. These techniques seem likely to prove useful in many other contexts. Finally, we have shown how the MTRI can be extended to allow for quotas for tariffs; and it can easily be extended further to account for the trade effects of domestic taxes and subsidies, using the methods of Anderson, Bannister and Neary (1995).

As for our empirical results, we found that on average the MTRI is correlated with the tradeweighted average tariff in comparisons with free trade and with changes in NTB restrictiveness in year-to-year comparisons of trade policy. However, it diverges significantly from both in individual cases, to an extent which makes standard atheoretic measures highly suspect in practice. Especially if tariffs are far from uniform, it seems highly desirable to use the MTRI rather than standard atheoretic measures to evaluate the restrictiveness of real-world protective structures. 


\section{References}

Anderson, J.E. (1995): "Tariff index theory," Review of International Economics, 3, 156-73.

Anderson, J.E. (1998): "Trade restrictiveness benchmarks," Economic Journal, 108, 1111-1125.

Anderson, J.E. and J.P. Neary (1992): "Trade reform with quotas, partial rent retention and tariffs," Econometrica, 60, 57-76.

Anderson, J.E. and J.P. Neary (1996): "A new approach to evaluating trade policy," Review of Economic Studies, 63, 107-125.

Anderson, J.E., G.E. Bannister and J.P. Neary (1995): "Domestic distortions and international trade," International Economic Review, 36, 139-157.

Bagwell, K. and R. Staiger (1997): "An economic theory of GATT," NBER Working Paper No. 6049; forthcoming in American Economic Review.

Corden, W.M. (1966): "The effective protective rate, the uniform tariff equivalent and the average tariff," Economic Record, 200-216.

Leamer, E. (1974): "Nominal tariff averages with estimated weights," Southern Economic Journal, 41, 34-46.

Neary, J.P. and A.G. Schweinberger (1986): "Factor content functions and the theory of international trade," Review of Economic Studies, 53, 421-432.

O'Rourke, K. (1997): "Measuring protection: A cautionary tale," Journal of Development Economics, 53, 169-183.

UNCTAD (1996): A User's Manual for TRAINS (TRade Analysis and INformation System), 
The Mercantilist Index of Trade Policy

New York and Geneva: United Nations. 